\title{
Toplam Faktör Verimliliği, Ekonomik Büyüme ve İhracat İlişkisi: Gelişmekte Olan Ülkeler Örneği
}

\author{
Hamza ÇEŞTEPE* $\quad$ Ersin ARSLAN ${ }^{* *} \quad$ Murat YAZICI $^{* * *}$ \\ $\ddot{O} Z$
}

Toplam faktör verimliliği, ekonomik büyüme ve ihracat, özellikle gelişmekte olan ülke ekonomileri için önemli makroekonomik büyüklüklerdir. Bu çalışmada, bu üç büyüklük arasindaki ilişki Dünya Bankası'nın güncel gelir gruplandırma kriterine göre üst orta gelirli ülkeler grubunda yer alan 26 gelişmekte olan ülke için, 1990-2017 dönemi verileriyle incelenmiştir. Panel nedensellik analizinin kullanıldı ̆̆ çalışmada, toplam faktör verimliliği ve ihracat arasında toplam faktör verimliliğinden ihracata doğru tek yönlü nedensellik ilişkisi bulunmuştur. Toplam faktör verimliliği ve ekonomik büyüme arasinda da çift yönlü nedensellik tespit edilmiştir. Elde edilen bulgular, gelişmekte olan ülkelerde toplam faktör verimliliğinin büyüme ve ihracatın başlıca nedenlerinden biri olduğunu göstermektedir. Nedensellik

Anahtar Kelimeler: Toplam Faktör Verimliliği, Ekonomik Büyüme, İhracat, Panel

JEL Sinıflandirması: F43, O33, 047

\section{The Relationship of Total Factor Productivity, Economic Growth and Exports: The Case of Developing Countries}

\begin{abstract}
Total factor productivity, economic growth and exports are important macroeconomic sizes, especially for developing economies. In this study, the relationship between these three sizes is analyzed with the data of 1990-2017 for 26 developing countries in the upper middle income countries group according to the current income grouping criteria of the World Bank. In the study in which panel causality analysis is used, one-way causality relationship is found between total factor productivity and exports from total factor productivity to exports. Bidirectional causality is also found between total factor productivity and economic growth. Findings indicate that, total factor productivity is one of the main causes of growth and exports in developing countries.
\end{abstract}

Key Words: Total Factor Productivity, Economic Growth, Exports, Panel Causality

JEL Classification: F43, O33, 047

\section{GíRIŞ}

Üretimle ilgili temel kavramlardan biri olan verimlilik, geniş ve dar anlamda iki şekilde kullanılmaktadır. Geniş anlamda verimlilik, ekonomik amaçlara ulaşmada araçların duyarlılık ve etkinliğini ifade eden bir kavram olarak tanımlanmaktadır. Dar anlamda ise, daha çok teknik bir terim olarak ele alınmakta

\footnotetext{
*Prof. Dr., Zonguldak Bülent Ecevit Üniversitesi, İktisadi ve İdari Bilimler Fakültesi, İktisat Bölümü, cestepe @ gmail.com, ORCID Bilgisi: 0000-0003-1541-5703

** Öğr. Gör., Sinop Üniversitesi, Gerze Meslek Yüksekokulu, Ulaştırma Hizmetleri Bölümü, e.a.ersinarslan@gmail.com, ORCID Bilgisi: 0000-0001-6647-1962

${ }_{* * *}^{*}$ Doktora Öğrencisi, Zonguldak Bülent Ecevit Üniversitesi, Sosyal Bilimler Enstitüsü, muratyazici5374@gmail.com, ORCID Bilgisi: 0000-0002-9037-9901
} 
ve üretim girdileri ile elde edilen çıktı arasındaki ilişkiyi ifade etmektedir. Gerek geniş anlamda, gerekse dar anlamda verimlilik tanımı bizi üretkenliğe götürmektedir. Günümüzde ülkeler arasındaki gelişmişlik düzeyindeki farklılıkların, temel olarak o ülkelerin verimlilik düzeyindeki farklılıklardan kaynaklandığı genel kabul görmekte ve verimlilik artışlarının büyüme ile kalkınmanın ana kaynakları arasında yer aldığı belirtilmektedir. Verimlilik, büyümenin en önemli belirleyicisi olarak ifade edilmekte; bu açıdan ülkeler arasındaki farklılıkların $\% 60$ oranında verimlilikten kaynaklandığ vurgulanmaktadir (Bahar, 2017).

Verimlilik ile büyüme arasındaki ilişki, özellikle 1950'li yıllardan günümüze kadar olan uzun dönemde iktisadi araștırmaların gözde konusu haline gelmiştir (Nordhaus, 2005). Verimlilik, büyüme ve kalkınmanın yanı sıra ülkelerin rekabet gücü, enflasyon, istihdam düzeyi gibi makro değişkenler üzerinde etkili olmaktadır. Verimlilikteki değişmelerin ekonomik kalkınma, yaşam standard1, ödemeler dengesi, enflasyonun kontrolü gibi ekonomik ve sosyal olayları etkilediği kabul edilmektedir (Uzay, 2008: 114).

Günümüzde verimlilik kavramı genellikle toplam faktör verimliliği kavramı ile birlikte anılmaya başlamıştır. Toplam faktör verimliliği (TFV) ülke ekonomilerinin büyümesinin temel unsurlarından biri durumundadır ve bu bağlamda, ülkelerin gelişme düzeylerindeki farklılıkları açıklayan önemli kavramlar arasında yer almaktadır (Alancıoğlu ve Şit, 2019: 1). TFV işgücü, sermaye gibi klasik üretim faktörlerinin ve teknolojinin ekonomik büyüme üzerindeki etkisini direkt olarak göstermesi yanında, aynı zamanda büyümenin mevcut durumunu ve gidişatını değerlendirmeye de olanak sağlamaktadır (Gömleksiz vd, 2017: 66). TFV, toplam çıktının girdilere oranlanması ile elde edilmektedir. Böylece üretim sürecindeki girdilerin üretimde sahip oldukları payı ve önemi görmek mümkün olmaktadır. Bu açıdan yüksek faktör verimliliğinin yüksek üretim gücü anlamına geldiği de söylenebilir.

Ekonomik büyümedeki artış, emek ve sermaye artışları ile sağlanır. Üretimde kullanılan sermaye miktarındaki artış iç kaynaklardan karşılanabileceği gibi, dış kaynaklardan da sağlanabilir. Dış kaynaklardan sağlanması durumunda ödemeler bilançosunda dengesizliklere neden olabilmekte, hatta cari açı̆̆a da sebebiyet verebilmektedir. Üretimde kullanılan emek miktarı ise nüfusa bağlıdır. Nüfus artışının zamansal bir değişken olduğunu dikkate aldığımızda mevcut girdilerin verimliliklerinin arttırılması, yani TFV artışı mevcut üretim düzeyinin yani çıktının artması anlamına gelmektedir. $\mathrm{Bu}$ bağlamda, TFV bir anlamda ekonomideki diğer değişkenlerin de temsili anlamı taşıdığından, burada meydana gelen olumlu değişiklikler ekonomiyi bütünsel anlamda olumlu yönde değiştirebilir. Aynı düzeyde çıktıyı daha az kaynakla elde edebilmek, mevcut kaynakların verimli başka alanlarda (Ar-Ge, beşeri sermaye vb.) değerlendirilmesine imkân sağlayabilir. Bu sayede bir anlamda ekonomik faaliyetin genişlemesi ve gelişmesi mümkündür.

İhracat, döviz kazancı sağlayan bir faaliyettir; bu nedenle ekonomik büyümenin motor güçlerinden biri olarak kabul edilir ve ülkelerin kalkınmalarını 
hızlandırmaya katkı sağlar. Ülkeler arası ticaretin uzmanlaşma sayesinde büyümeyi arttırdığ1 ve ticaret yapan ülkeler arasında refah artışına yol açtığ 1 düşüncesi, merkantilizm dönemine kadar uzanan eski bir konudur (Bal vd., 2016: 311). 1970'li yıllardan itibaren, ihracat ve ekonomik büyüme ilişkisi üzerinde artan bir ilgi oluşmuştur. $\mathrm{Bu}$ bağlamda ihracata dayalı büyüme ve büyümeye dayalı ihracat modelleri geliştirilmiştir.

İhracata dayalı büyüme modeline göre, ihracat artışı teknolojik yeniliklerin adaptasyonunu kolaylaştırmakta ve kaynak kullanımında etkinliği artırmaktadır. Başka bir ifadeyle, ihracat verimliliği artırmakta, bu da büyümenin hızlanmasına yol açmaktadır (Uçak ve Arısoy, 2011: 649). Ancak, ihracat ile büyüme arasındaki ilişki tek yönlü değildir. İhracat büyümeye neden olurken, ekonomik büyüme de verimlilik ve etkinlik artışı kanalıyla uluslararası piyasalarda daha rekabetçi ihracatın yapılmasına yol açar (Santos vd., 2013). Buna karşılık, büyümeye dayalı ihracat modelinde ise büyümenin uzmanlık ve teknolojiyi geliştirme yoluyla verimlilik artışları sağladığı, bunun da karşılaştırmalı üstünlük yaratarak ülkelerin ihracatını kolaylaştırdığı ifade edilmektedir (Giles ve Williams, 1999: 3). Bu bağlamda çalışmanın temel amacı, gelişmekte olan ülkeler örneğinde, ekonomik büyüme ve ihracat ile TFV arasındaki nedensellik ilişkisinin analiz edilmesidir.

TFV ile büyüme ve özellikle ihracat ile büyüme ilişkisi konusunda yerli ve yabancı literatürde çok sayıda çalışma olmasına rağmen, üç büyüklük arasındaki ilişkiyi inceleyen fazla çalışma bulunmamaktadır. Çalışmanın bu anlamda literatüre katk1 sağlayacağı değerlendirilmektedir. Bunun yanında, orta gelirli gelişmekte olan ülkeler örneği üzerinde ekonometrik analizin yapılmış olması da, çalışmanın bu alandaki diğer çalışmalardan farkını ortaya koymaktadır.

Çalışmada ilk olarak konuyla ilgili ampirik literatür hakkında bilgi verilmiştir. Takip eden bölümde çalışmada kullanılan veri seti ve yöntemden bahsedilmiştir. Üçüncü bölümde ekonometrik analiz başlığı altında gerekli testler yapılmış ve bunların sonuçları değerlendirilmiştir. Çalışmanın sonunda ise, ulaşılan temel sonuçlar yer almaktadır.

\section{LITERATÜR INCELEMESI}

TFV kavramına yönelik çalışmalar, ekonomide mevcut üretim faktörleri ile daha fazla çıtı elde etmeye yönelik modellemelerdir. Bu anlamda bu alana ilişkin ilk çalışmaların, Solow'un (1956) geliştirdiği büyüme modeline dayanmakta olduğu ifade edilebilir. Solow (1956)'a göre, tam rekabet piyasası koşulları altında dışsal olarak ele alınan teknoloji ile, üretimde elde edilen artışlar verimlilik artışlarıdır. Neo klasik büyüme modeli olarak adlandırılan Solow modeli, emek ve sermayeye beşeri sermaye de eklemlenerek geliştirilmiştir.

TFV ile ilgili çalışmalar, genel olarak ülke bazında ya da ülke grupları bazında yapılan çalışmalardan oluşmaktadır. Bu çalışmalarda çeşitli değişkenlerin kullanıldığı görülmektedir. Genel literatürde toplam faktör verimliliği ile büyüme ve ihracat arasında güçlü bir nedensellik ilişkisinin varlığı kabul edilmekle birlikte, toplam faktör verimliliğinin ithalat ve ekonomide dışa açıklık analizlerinde kullanımına yönelik bir eğilimin oluştuğu da görülmektedir. 
TFV ile ilgili çalışmalara geçmeden önce, diş ticaret ve ekonomik büyüme ilişkisini inceleyen çalışmalardan bahsetmek gerekirse, bu çalışmalarda daha çok ihracat ve büyüme ilişkisi araştırılmıştır (Chow, 1987; Paul ve Chowdhury 1995; Xu, 1996; Ekanayake vd., 1999; Hatemi-J, 2002; Konya, 2004, Jordaan ve Eita, 2007; Yaprakl1, 2007; Chang vd., 2013; Ajmi vd., 2015). Bu çalışmalarda genel olarak ihracatın ekonomik büyüme üzerinde olumlu bir etkiye sahip olduğu görülmüştür. Örneğin Hatemi-J (2002) çalışmasında, Japonya'da ihracat artışı ile ekonomik büyüme arasındaki nedensel ilişkiyi, Bootstrap simülasyon tekniğini kullanarak artırılmış Granger nedensellik testleriyle incelemiştir. Sonuçlar, Granger nedenselliğinin 1960-1999 dönemi için iki yönlü olduğunu göstermektedir. Yerleşik iki yönlü nedensellik, ihracatın genişlemesinin Japonya'daki ekonomik büyüme sürecinin ayrılmaz bir parçası olduğunu göstermiştir. İthalatın ekonomik büyüme üzerindeki etkisini inceleyen çalışmalarda (Ramos, 2001; Awokuse, 2008; Aktaş, 2009; Albimon ve Suleiman, 2016; Trošt ve Bojnec, 2016; Bhattacharya ve Bhattacharya, 2017; Bakari, 2017) ithalatın ihracatla birlikte ekonomik büyümeye etkisi incelenmiş ve ithalatın da genel olarak ekonomik büyümeyi olumlu yönde etkilediği sonucuna ulaşılmıştır.

TFV, büyüme ve diş ticaret değişkenlerini kullanarak yapılan çalışmalara baktığımızda, bunlardan biri olan Hacker ve Hatemi-J (2003) tarafindan İsveç üzerine yapılan çalışmada, verimlilik ve yerli çıktının ihracat ve yabancı çıktıyla nasıl bir ilişkiye sahip olduğu araştırılmıştır. Adı geçen yazarlar 1970-1999 dönemi için ihracat, TFV ve GSYİH değişkenlerinin ikili setini kullanarak yaptıkları çalışmada, Vektör Hata Düzeltme Modeli (VECM) ve Toda-Yamamoto prosedürünü takip ederek Granger Nedensellik Testi uygulamışlardır. Yapılan testler sonucunda, İsveç'in reel ihracatı ve reel GSYİH'si (ya da TPV'si) arasında iki yönlü nedensellik ilişkisi tespit edilmişsir.

Thangavelu ve Rajaguru (2004)'nun çalışmasında, seçili ülkelerin verileri üzerinden vektör hata düzeltme modeli kullanılarak zaman serisi analizi yapılmıştır. Ampirik sonuçlar, dış ticaretin ekonomideki verimlilik ve üretim büyümesi üzerinde önemli bir etkiye sahip olduğunu göstermiştir. Yapılan analiz sonucu, uzun vadede TFV üzerinde olumlu nedensel etkiyi yaratan faktörün, ihracattan daha çok ithalat olduğu görülmüştür.

Kim ve Lim (2005), 1980-2003 döneminde Güney Kore'de ticaret ve ekonomik büyüme arasındaki ilişkiyi araştırmıştır. Ampirik sonuçlar, ithalattan TFV büyümesine Granger nedenselliğinin varlığını ve ihracat ile TFV arasında nispeten zayıf nedensel ilişkinin olduğunu göstermektedir. Sonuçlar, aynı zamanda ithalatın TFV büyümesi üzerindeki etkisinin sadece rekabet baskısından ve nihai mal ithalatı arttıkça yabancı rakiplerden edinilen yeni bilgilerden değil, aynı zamanda gelişmiş ülkelerden yapılan ithalatta somutlaşan teknoloji transferlerinden kaynaklandığını göstermiştir. Benzer şekilde Kim vd. (2009), 1980-2003 yılları arasında Güney Kore'nin ithalat ve ihracatının TFV üzerindeki etkisini incelemişlerdir. Çalışmada yine ithalattan TFV büyümesine Granger nedenselliğine ulaşılırken, ihracat ve TFV arasında herhangi bir nedenselliğin bulunmadığı tespit edilmiştir. 
Rath ve Akram (2017) ise, 1995-2014 yılları arasında Güney Asya'ya ait yıllık verileri kullanarak TFV ile ihracat çeşitlendirmesi arasındaki ilişkiyi incelemişlerdir. Panel eşbütünleşme analizinden elde edilen ampirik sonuçlar, TPV ile ihracat çeşitlendirilmesi arasında uzun dönemli ilişki bulunduğunu göstermiştir. Ayrıca, DOLS'a dayalı sonuçlar ihracat çeşitlendirmesinin uzun vadede TFV büyümesine neden olduğunu, ancak kısa vadede nedensellik bulunmadığını göstermektedir.

Konuyla ilgili yerli literatürde ilk çalışmalardan birini yapan Vergil ve Abasız (2008), çalışmalarında Türkiye için toplam faktör verimliliği tahmini yaptıktan sonra, Collins Bosworth varyans ayrıştırması yöntemini kullanarak üç ayrı model yoluyla TFV'nin büyüme üzerindeki etkisini incelemişlerdir. Adı geçen yazarlar, talepteki dalgalanmaları ve durağan durumdaki bir ekonomiyi dikkate aldıkları bu çalışmada, TFV düzeyinin ekonomik büyümeyi pozitif etkilediği sonucuna varmışlardır. Çalışmada ayrıca, TFV artışlarının ekonomik büyümenin \%30'unu oluşturduğu sonucu da elde edilmiştir.

Uçak ve Arısoy (2011), çalışmalarında Türkiye ekonomisi üzerinde gerçekleştirdikleri nedensellik analizi doğrultusunda, ithalat ve ihracatın uzun dönemde verimlilik artışına pozitif yönde etki sağladığını, özellikle dış ticaretin gelişmesinin TFV için önemli bir faktör olduğunu tespit etmişlerdir. BRICS ülkelerinde 2001-2015 yılları arasında ithalat aracıllı̆ııla yurtdışı Ar-Ge faaliyetlerinin ve doğrudan yabancı yatırımların TFV'ye etkisini panel veri analiziyle inceleyen Akkoç vd. (2018) ise, ithalat yapılan ülkelerdeki Ar-Ge harcamalarının ev sahibi ülkenin TFV'sini belirgin bir şekilde artırdığını, doğrudan yabancı yatırımların ise TFV'yi artırmakla birlikte Ar-Ge çalışmalarından daha düşük bir etkiye sahip olduğunu tespit etmişlerdir.

Yalçınkaya (2016), toplam faktör verimliliği ile uzun dönemde ekonomik büyümenin sürdürülebilir hale getirilmesi ve hızının artırılması arasındaki bağlantıyı araştırmıştır. Bu doğrultuda G-7 ülkeleri ile Yükselen Piyasa Ekonomisi Ülkeleri (YPE-9)'nin, belirli dönemdeki verileri 1şığında karşılaştırması yapılmıştır. YPE-9 ülkelerinde fiziksel sermayeye yapılan yatırımların toplam faktör verimliliğini artırdığı, buna karşılık G-7 ülkelerinde ise bilgi, inovasyon, fiziksel sermaye ve teknolojik gelişmişlik düzeyini belirlemek için kullanılan hemen hemen tüm değişkenlerin TFV üzerinde önemli bir etkiye sahip olduğu belirlenmiştir.

Gömleksiz vd. (2017), çalışmalarında toplam faktör verimliliği üzerinde Ar-Ge, ileri teknolojili ürünlerin ithalat1, beşeri sermaye ve ticari dışa açıklığın etkilerini karşılaştırmalı olarak incelemek için 12 OECD ülkesine ait verileri kullanmışlardır. Yaptıkları analiz sonucunda beşeri sermayenin anlamlı bir değişime neden olmadığını; ancak Ar-Ge, ileri teknolojili ürünlerin ithalatı ve dışa açıklığın verimlilik artışında önemli birer faktör olduğunu tespit etmişlerdir.

Literatür genel olarak değerlendirildiğinde, diş ticaret ve ekonomik büyümenin toplam faktör verimliliği üzerinde olumlu bir etkiye sahip olduğunu ifade etmek mümkündür. Bununla birlikte çalışmalarda elde edilen sonuçların, ele 
alınan dönem ve ülke örnekleri yanında ithalat ve ihracat değişkenlerine göre de farklılaşabildiği görülmektedir.

\section{VERİ SETI VE YÖNTEM}

Çalışmanın ekonometrik analiz bölümünde, toplam faktör verimliliği ile ihracat ve büyüme arasındaki ilişkinin gelişmekte olan ülkeler örneğinde incelenmesi hedeflenmiştir. Analize dâhil edilen ülkeler verilerin temin edilebilirliğine göre, Dünya Bankası'nın 2019 yılına ait gelir gruplandırma kriteri dikkate alınarak seçilmiştir. Dünya Bankası gelişmişlik düzeyi sıralamasında gelir kriterini kullanmaktadır. 1.025 \$ ve altı kişi başı gelire sahip ülkeler az gelişmiş ülkeler olarak kabul edilmektedir. 1.026 \$ ile 12.375 \$ aralığındaki ülkeler gelişmekte olan ülkeler olarak kabul edilirken, 12.376 \$ ve üzeri kişi başı gelire sahip ülkeler ise gelişmiş ülkeler olarak adlandırılmaktadır. Dünya Bankası sıralamasında gelişmekte olan ülkeler, alt orta gelirli ve üst orta gelirli ülkeler şeklinde iki kısma ayrılmaktadır. Alt orta gelir grubu ülkeleri $1.026 \$$ ile $3.995 \$$ aralığında yer alan ülkelerdir. $3.996 \$$ ile $12.375 \$$ aralığında yer alan ülkeler üst orta gelir düzeyini temsil etmektedir (World Bank, 2020). Bu çalışmada, Dünya Bankası'nın sınıflandırmasına göre üst orta gelir grubunda yer alan şu 26 ülkenin verileri kullanılmıştır: Arjantin, Brezilya, Bulgaristan, Bostwana, Çin, Dominik Cumhuriyeti, Ekvator, Gabon, Guatemala, Güney Afrika Cumhuriyeti, İran, Irak, Jamaika, Kolombiya, Kostarika, Malezya, Mauritius, Meksika, Namibya, Paraguay, Peru, Romanya, Tayland, Türkiye, Ürdün, Venezuela. Çalışmada, toplam faktör verimliliği (TFV) endeksi, gayrisafi yurtiçi hâsıla (GSYİH-milyon ABD doları) ve ihracatın GSYİH'ye oranı (\%) verileri kullanılmıştır. GSYIH rakamları sağlıklı sonuçlar elde edilebilmesi için logaritmaları alınarak analize dâhil edilmiştir. Veriler 1991-2017 yıllarına ait olup, alındığı kaynaklar Tablo 1'de gösterilmektedir.

Tablo 1. Değişkenler ve Veri Kaynakları

\begin{tabular}{|l|c|l|}
\hline Değişken Adı & Kısaltma & Kaynak \\
\hline Toplam Faktör Verimliliği Endeksi & TFV & Penn World Table, version 9.1 \\
\hline Gayri Safi Yurtiçi Hâsıla & GSYİH & Dünya Bankası \\
\hline İhracat Oranı (\%GSYİH) & İHR & Dünya Bankası \\
\hline
\end{tabular}

Analizde, öncelikli olarak panel veri setinde yatay kesit bağımlılığı Pesaran (2004) CD testi ile kontrol edilmiştir. Ardından, çıkan sonuçlara göre serilerin durağanlıklarını test etmek amacıyla, aynı anda birinci ve ikinci nesil birim kök testlerinden Maddala ve Wu (1999)'nun MW testi ve Paseran (2007)'in CIPS testi sonuçları elde edilmiş ve serilerin durağanlık kontrolü yapılmıştır. Serilerin durağanlıklarının tespitinden sonra, VAR modelinin kurulabilmesi amacı ile uygun gecikme uzunluğu tespit edilmiş; elde edilen bu gecikme uzunluğu ile GMM metodu kullanılarak parametre tahminleri yapılmışır. Parametre tahminin ardından, modelin dinamik stabilite koşulunu taşıyıp taşımadığı kontrol edilmiştir. Dinamik stabilite şartının sağlanmasını takiben etki tepki grafikleri elde edilmiş, varyans ayrıştırması yapılmış ve son olarak da değişkenler arasında Granger nedensellik ilişkisinin olup olmadığ 1 araştırılmış ve elde edilen sonuçlar yorumlanmıştır. 


\section{EKONOMETRİK ANALIZZ}

Çalışmanın bu bölümünde yatay kesit bağımlılı̆̆ının kontrolünden sonra birim kök testleri yapılacak, daha sonra da toplam faktör verimliliği ile ihracat ve gelir düzeyi arasındaki ilişki gerekli testlerle ortaya konulacaktır.

\section{A. Yatay Kesit Bağımlıığı}

Panel veri uygulamalarının ilk olarak uygulanmaya başlandığı dönemlerde yatay kesit bağımlılığ 1 göz ardı edilmiştir. Ancak, sonraki dönemlerde panel veri setinde yer alan değişkenler arasında yatay kesit bağımlılığının kontrolünün analizin sonuçları açısından önemli olduğu ifade edilmiştir (Pesaran, 2004). Dolayısıyla, panel veri setinde yatay kesit bağımlılığının kontrol edilmesi gerekmektedir. Bu çalışmada Pesaran tarafindan 2004 yılında geliştirilen CD testi uygulanmıştır. Pesaran CD testi her bir panel üyesi için zaman serileri arasındaki korelasyon katsayılarını kullanmaktadır. Bu katsayılarla elde edilen CD aşağıdaki gibi tanımlanmaktadır (Şak, 2018: 309):

$C D=\sqrt{\frac{2 T}{N(N-1)}}\left(\sum_{i=1}^{N-1} \sum_{J=i+1}^{N} \rho^{\wedge} \mathrm{ij}\right) \sim \mathrm{N}(0,1) \quad \mathrm{i}, \mathrm{j}=1, \ldots \ldots \ldots, \mathrm{N}$

Burada $\rho \wedge$ ij ifadesi, artıkların ikili korelasyonları örneklem tahminini ifade etmektedir. CD testi diğer yatay kesit bağımlılık testlerine göre modelleme öncesinde tahmin yapmadan sonuçları hesaplayabilmektedir. Ayrıca, tüm değişkenlerin aynı anda test sonuçlarını elde etmek mümkün olmaktadır.

CD testinde hipotezler;

Ho: $\rho^{\wedge} \mathrm{ij}=\operatorname{cor}\left(u_{i t}, u_{j t}\right)=0 \mathrm{i} \neq \mathrm{j} \quad$ Yatay kesit bağımlılı̆̆ 1 yoktur.

Ha: $\rho \hat{\mathrm{ij}}=\operatorname{cor}\left(u_{i t}, u_{j t}\right) \neq 0 \mathrm{i} \neq \mathrm{j} \quad$ Yatay kesit bağımlılığı vardır, şeklinde kurulmaktadır.

Çalışmada uygulanan CD testi sonucunda GSYİH, ihracat ve TFV değişkenlerine ait elde edilen sonuçlar Tablo 2'de yer almaktadır.

Tablo 2. CD Testi Sonuçları

\begin{tabular}{|c|c|c|}
\hline Değişken Adı & CD Test Sonucu & Olasılık Değeri \\
\hline LGSYİH & 87,88 & 0,0000 \\
\hline IHR & 11,10 & 0,0000 \\
\hline TFV & 8,62 & 0,0000 \\
\hline
\end{tabular}

CD testinde Ho hipotezi yatay kesit bağımsızlı̆ Tabloda yer alan olasılık değerleri incelendiğinde tüm seriler için $\% 1, \% 5$ ve $\% 10$ anlamlılık düzeylerinde Ho hipotezinin reddedildiği görülmektedir. Bu sonuçlara göre, tüm seriler yatay kesit bağımlılı̆g 1 içermektedir. Bu durumda, durağanlık sınamalarının ikinci nesil birim kök testleri ile yapılması gerektiğine karar verilmiştir.

\section{B. Birim Kök Testleri}

Panel veri modellerinin ilk artış gösterdiği dönemlerde yatay kesit bağımlılığı dikkate alınmadığından, birinci nesil testler olarak adlandırılan birim kök testleri kullanılmıştır. Birinci nesil birim kök testlerinden en sık kullanılanları Levin-Lin ve Chu (LLC), Breitung, Im-Pesaran ve Shin (IPS), Fisher ADF, Fisher PP ve Hadri birim kök testleridir. Panelde yer alan serilerde yatay kesit bağımlılı̆̆ının tespiti durumunda ise ikinci nesil birim kök testleri daha tutarlı, etkin ve güçlü sonuçlar verebilmektedir. 
Birinci nesil testler, paneli oluşturan yatay kesit birimlerinin ilişkisiz olduğunu ve oluşan bir şokun yatay kesit birimlerini aynı düzeyde etkilediğini varsaymaktadır. Ancak, hızla küreselleşen ve ekonomik ilişkilerin daha karmaşık hale geldiği günümüz dünyasında tüm aktörlerin eşit şekilde etkilendiğini varsaymak gerçekçilikten uzaklaşmaya neden olmaktadır. Buradan yola çıkarak geliştirilen ikinci nesil birim kök testleri ile sonuçların daha gerçekçi olmaları amaçlanmaktadır.

İkinci nesil birim kök testleri arasında en çok kullanılanlar, SURADF (Breuer, Mcknown ve Wallace, 2002), Bai ve Ng (2004), CADF (Pesaran, 2007) testleridir. Bu çalışmada Pesaran tarafından geliştirilen CADF testi kullanılmıştır. Ancak birinci nesil ve ikinci nesil birim kök testlerini aynı anda görebilmek amacı ile Maddala ve Wu (1999) ve Pesaran (2007) test sonuçları birlikte verilmiştir. Maddala ve Wu testi DF (Dickey Fuller) temelli bir testtir. Heterojenliği varsaymaktadır, ancak yatay kesit bağımlılı̆̆ını göz ardı etmektedir. CADF (crosssectionally augmented ADF) testi ise Pesaran tarafindan 2007 y1lında geliştirilmiştir.

CADF testi ile her bir yatay kesit için birim kök testi yapılabilmekte ve serilerin durağanlığı, tüm panel için ve yatay kesitler için ayrı ayrı hesaplanabilmektedir. Her ülkenin etkilendiği zaman etkilerinin farklı olduğunu varsayan ve mekânsal otokorelasyonu dikkate alan CADF testi, $\mathrm{T}>\mathrm{N}$ ve $\mathrm{N}>\mathrm{T}$ durumunda kullanılmaktadır (Mercan vd, 2015:129).

Pesaran $(2003,2007)$, çalışmasında bireysel CADF testlerine dayandırdığı birim kök testinde IPS tarafindan önerilen t-bar testinin daha genelleştirilmiş hali üzerine yoğunlaşmış ve IPS testinin yatay kesit olarak genişletilmiş bir şeklini dikkate almıştır (İnal, 2009: 40). Diğer bir ifadeyle, CIPS (cross-sectionally augmented IPS) testi IPS testinin yatay kesit bağımlılığı için uyarlanmış halidir ve aşağıdaki gibi gösterilebilir:

$$
\operatorname{CIPS}(N, T)=N^{-1} \sum_{i=1}^{N} t_{i}(N, T)
$$

Denklemde yer alan $t_{i}(N, T)$ ifadesi CADF regresyonunda yer alan yatay kesit birimi için elde edilen CADF istatistiğini ifade etmektedir. Tablo 3, yapılan birim kök testlerinin sonuçlarını göstermektedir.

Tablo 3. Birim Kök Test Sonuçları

\begin{tabular}{|c|c|c|c|c|}
\hline \multicolumn{5}{|c|}{ Düzey Değerlerinde } \\
\hline \multicolumn{3}{|c|}{ Maddala-Wu } & \multicolumn{2}{|c|}{ CIPS } \\
\hline Değişken & Trendsiz Model & Trendli Model & Trendsiz Model & $\begin{array}{l}\text { Trendli Model } \\
\end{array}$ \\
\hline LGSYİH & 1,000 & 0,091 & 0,224 & 0,963 \\
\hline TFV & 0,000 & 0,036 & 0,283 & 0,151 \\
\hline 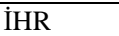 & 0,012 & 0,076 & 0,433 & 0,156 \\
\hline \multicolumn{5}{|c|}{ İlk Farkı Alındığında } \\
\hline LGSYİH & 0,000 & 0,000 & 0,000 & 0,000 \\
\hline TFV & 0,000 & 0,000 & 0,000 & 0,000 \\
\hline İHR & 0,000 & 0,000 & 0,000 & 0,000 \\
\hline
\end{tabular}

Tablo incelendiğinde iki testin farklı sonuçlar verdiği görülmektedir. Değişkenlerin düzey değerlerinde birim kök içerdikleri, ilk farkları alındığında ise birim kök içermedikleri görülmektedir. Bu sonuçlara göre, panel VAR modelinin 
kurulabilmesi için gerekli olan serilerin aynı düzey değerlerinde durağanlık şartını taşımaları koşulu gerçekleşmiştir.

\section{Panel VAR Analizi}

VAR modelleri, birbiri ile karş1lklı ilişki içerisinde olduğu düşünülen değişkenlerin etkileşimlerini ortaya koymak için kullanılan modellerdir. Modelde yer alan her bir değişken, kendi ve diğer değişkenlerin gecikmeli değerleri ile açıklanmaktadır. İktisadi değişkenler arasında içsel ve dışsal olma ayrımını ortadan kaldırdığından sıklıkla kullanılmaktadır. Panel VAR modelleri, geleneksel VAR modellerinin panel verilere uygulanmış halidir (Güriş, 2018: 397). Bu çalışmada kullanılan değişkenler için oluşturulan modeller aşağıdaki eşitliklerde verilmektedir:

$T F V_{i t}=\sum_{j=1}^{J} \alpha_{11 j} T F V_{i, t-j}+\sum_{j=1}^{J} \alpha_{12 j} I H R_{i, t-j}+\sum_{j=1}^{J} \alpha_{13 j} L G S Y I H_{i . t-j}+\lambda_{1 i 0}+$ $\lambda_{10 t}+\varepsilon_{1 i t}$

$\operatorname{LGSYIH}_{i t}=\sum_{j=1}^{J} \alpha_{21 j} \operatorname{LGSYIH}_{i, t-j}+\sum_{j=1}^{J} \alpha_{22 j} I H R_{i, t-j}+\sum_{j=1}^{J} \alpha_{23 j} \operatorname{TFV}_{i . t-j}+\lambda_{2 i 0}+$ $\lambda_{20 t}+\varepsilon_{2 i t}$

$I H R_{i t}=\sum_{j=1}^{J} \alpha_{31 j} I H R_{i, t-j}+\sum_{j=1}^{J} \alpha_{32 j} L G S Y I H_{i, t-j}+\sum_{j=1}^{J} \alpha_{33 j} T_{F V} V_{i . t-j}+\lambda_{3 i 0}+$ $\lambda_{30 t}+\varepsilon_{3 i t}$

Denklemlerde $\lambda_{1 i 0} \lambda_{\mathbf{2 i 0}} \lambda_{\mathbf{3 i 0}}$ ifadeleri birim etkisini, $\lambda_{10 t} \lambda_{20 t} \lambda_{\mathbf{3 0 t}}$ ifadeleri gözlenemeyen zaman etkilerini, $\varepsilon_{1 i t} \varepsilon_{2 i t} \varepsilon_{3 i t}$ ifadeleri de hata terimlerini göstermektedir. $J$ maksimum gecikme uzunluğu ise, bilgi kriterleri aracıllğı ile belirlenmektedir. Bu aşamada VAR modelinin uygulanması aşamasına geçilmeden önce değişkenler için uygun gecikme uzunluğunun tespiti yapılmıştır ${ }^{1}$.

Tablo 4. Gecikme Uzunluğunun Tespiti Sonuçları

\begin{tabular}{|c|c|c|c|c|c|c|}
\hline Gecikme & CD & J & Jp-değeri & MBIC & MAIC & MQIC \\
\hline $\mathbf{1}$ & .4732494 & 30.07616 & .3107427 & -141.3506 & -23.92384 & -69.73308 \\
\hline $\mathbf{2}$ & .6351676 & 16.97842 & .524589 & -97.30608 & -19.02158 & -49.56107 \\
\hline $\mathbf{3}$ & .2517245 & 14.06175 & .1201457 & -43.08051 & -3.938255 & -19.208 \\
\hline
\end{tabular}

Açıklamalar: Gözlem Aralığı: 1995-2017, Gözlem Sayısı: 572, Birim Sayısı: 26

Tablo 4'deki değerler incelendiğinde örneklemin başlangıç yılının 1995 olduğu görülmektedir. $\mathrm{Bu}$ durum, gecikme uzunluğunun tespitinde ilk 4 gecikmenin VAR modeli tahmininde kullanılmasından kaynaklanmaktadır. Sonuçlar bilgi kriterlerinin değerleri açısından ele alındığında, modifiye edilmiş Bayesyan, modifiye edilmiş Akaike ve modifiye edilmiş Hannan-Quinn bilgi kriterlerinde en küçük değerlerin yer aldığ 1 gecikme uzunluğu, uygun gecikme uzunluğu olarak kabul edilmiştir. Gecikme uzunluğunun tespitinin ardından GMM (Genelleştirilmiş Momentler Metodu) yöntemi ile VAR modelinin sonuçları tahmin edilmiştir. Elde edilen sonuçların anlamlı olabilmesi için modelin stabilite şartını sağlaması gerekmektedir.

Stabilite şartının sağlanması için modelde yer alan değişkenlerin uygun gecikme uzunluğundaki AR köklerinin birim çember içerisinde yer alması, diğer bir ifade ile 1'den küçük olması gerekmektedir. Elde edilen birim çember sonuçları ve tablosu aşağıda verilmektedir.

\footnotetext{
${ }^{1}$ VAR modeli için uygun gecikme uzunluğunun tespitinde, Abrigo ve Lowe tarafindan 2016 y1lında Panel VAR modeli için geliştirilen Stata program kodları kullanılmıştır.
} 
Hamza Çeştepe \& Ersin Arslan \& Murat Yazıcı / Toplam Faktör Verimliliği, Ekonomik Büyüme ve İhracat Ilişkisi: Gelişmekte Olan Ülkeler Örneği

Tablo 5. Özdeğerler

\begin{tabular}{|c|c|c|}
\hline \multicolumn{2}{|c|}{ Özdeğerler } & \multirow{3}{*}{$\frac{\text { Modül }}{.2726634}$} \\
\hline Reel & İmaginel & \\
\hline 2726634 & 0 & \\
\hline .0662656 & .1164295 & 1339662 \\
\hline .0662656 & -.1164295 & .1339662 \\
\hline
\end{tabular}

Grafik 1. Birim Çember Sonuçları

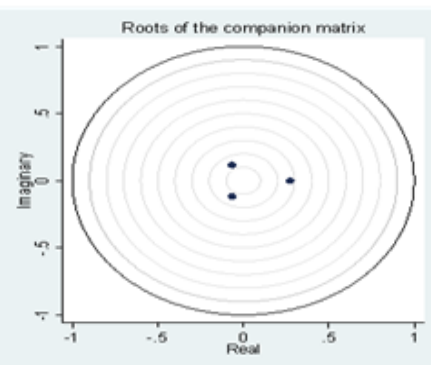

Grafik 1 incelendiğinde, tüm öz değerlerin birim çember içerisinde yer aldıkları görülmektedir. Ayrıca, Tablo 5 değerlerine bakıldığında tüm değerlerin 1 'den küçük oldukları görülmektedir. Bu sonuçlara göre 1 gecikme uzunluğunda tahmin edilen VAR modeli stabilite şartını sağlamaktadır.

Modelin stabilite şartının sağladığının tespitinden sonra sırasıyla varyans ayrıştırması ve etki-tepki fonksiyonlarının izlenmesi gerekmektedir. Varyans ayrıştırması, VAR modelinde yer alan değişkenlerin uygun gecikme uzunluğunda kendisi ve diğer değişkenleri açıklama gücüdür. Etki tepki analizleri ise, değişkenlerden birinde meydana gelen pozitif bir birimlik şokun, kendisi ve diğer değişkenlerde meydana getirdiği tepkinin ölçülmesinde kolaylık sağlamaktadır.

Tablo 6. DLGSYİH için Varyans Ayrıştırması

\begin{tabular}{|c|c|c|c|}
\hline Tepki Değişkeni DLGSYİH & \multicolumn{3}{|c|}{ Etki Değişkeni } \\
\hline Dönem & DLGSYïH & DïHR & DTFV \\
\hline $\mathbf{1}$ & 1 & 0 & 0 \\
\hline $\mathbf{2}$ & .9577438 & .0174818 & .0247744 \\
\hline $\mathbf{3}$ & .9537991 & .0201231 & .0260778 \\
\hline $\mathbf{4}$ & .9537198 & .020209 & .0260711 \\
\hline $\mathbf{5}$ & .9537128 & .0202171 & .0260702 \\
\hline $\mathbf{6}$ & .953712 & .0202178 & .0260702 \\
\hline $\mathbf{7}$ & .953712 & .0202178 & .0260702 \\
\hline $\mathbf{8}$ & .953712 & .0202178 & .0260702 \\
\hline $\mathbf{9}$ & .953712 & .0202178 & .0260702 \\
\hline
\end{tabular}

Varyans ayrıştırması sonuçlarına göre, GSYİH'nin bağımlı değişken olduğu modelde Tablo 6'da görüldüğü gibi, GSYİH'de meydana gelen değişmelerin \% 95,77 oranında kendisi tarafından, \%1,74 oranında ihracat tarafından, $\% 2,47$ oranında ise toplam faktör verimliliği tarafından açıklanmaktadır. 2. dönemden itibaren GSYİH'nin kendisi tarafından açıklanma oranının bir miktar azaldığı, ihracat ve toplam faktör verimliliğinin açıklama gücünün ise bir miktar arttı̆̆ görülmektedir.

Tablo 7. DIHR için Varyans Ayrıştırması

\begin{tabular}{|c|c|c|c|}
\hline Tepki Değişkeni DLGSYİH & \multicolumn{3}{|c|}{ Etki Değişkeni } \\
\hline Dönem & DLGSYİH & DİHR & DTFV \\
\hline $\mathbf{1}$ & .0952913 & .9047086 & .1772579 \\
\hline $\mathbf{2}$ & .1115592 & .711183 & .1800974 \\
\hline $\mathbf{3}$ & .112003 & .7078996 & .18008 \\
\hline $\mathbf{4}$ & .1120884 & .7078316 & .1800784 \\
\hline $\mathbf{5}$ & .112096 & .7078255 & .1800784 \\
\hline $\mathbf{6}$ & .1120965 & .7078251 & \\
\hline
\end{tabular}




\begin{tabular}{|c|c|c|c|}
\hline $\mathbf{7}$ & .1120966 & .7078251 & .1800783 \\
\hline $\mathbf{8}$ & .1120966 & .7078251 & .1800783 \\
\hline $\mathbf{9}$ & .1120966 & .7078251 & .1800783 \\
\hline $\mathbf{1 0}$ & .1120966 & .7078251 & .1800783 \\
\hline
\end{tabular}

İhracatın bağımlı değişken olduğu modelde, bu değişkende meydana gelen değişmelerin ikinci dönemde $\% 71,11$ oranında kendisi tarafindan, $\% 11,15$ oranında GSYIH tarafindan, \%17,72 oranında ise toplam faktör verimliliği tarafindan açıklanabildiği görülmektedir.

Tablo 8. DTFV için Varyans Ayrıştırması

\begin{tabular}{|c|c|c|c|}
\hline Tepki Değişkeni DLGSYIH & \multicolumn{3}{|c|}{ Etki Değişkeni } \\
\hline Dönem & DLGSYiH & DïHR & DTFV \\
\hline $\mathbf{1}$ & .0749383 & .0515354 & .8735272 \\
\hline $\mathbf{2}$ & .070172 & .0553074 & .8745205 \\
\hline $\mathbf{3}$ & .0701932 & .0553618 & .8744451 \\
\hline $\mathbf{4}$ & .070198 & .0553632 & .8744388 \\
\hline $\mathbf{5}$ & .0701982 & .0553633 & .8744385 \\
\hline $\mathbf{6}$ & .0701982 & .0553633 & .8744384 \\
\hline $\mathbf{7}$ & .0701982 & .0553633 & .8744384 \\
\hline $\mathbf{8}$ & .0701982 & .0553633 & .8744384 \\
\hline $\mathbf{9}$ & .0701982 & .0553633 & .8744384 \\
\hline $\mathbf{1 0}$ & .0701982 & .0553633 & .8744384 \\
\hline
\end{tabular}

Toplam faktör verimliliğinin bağıml değişken olduğu modelde ise, Tablo 8'den de izlenebileceği gibi, TFV'deki değişmelerin \%7,49 oranında GSYİH tarafından açıklandığ 1 görülmektedir. $\% 87,35$ oranında kendisi tarafından açıklanabilmektedir. Yaklaşı $\% 5,15$ oranında ise, ihracat tarafindan açıklanabildiği görülmektedir.

Varyans ayrıştırmasının ardından etki-tepki fonksiyonlarının grafikleri elde edilmiştir. Değişkenlerde meydana gelen bir birimlik pozitif bir şokun meydana getirdiği etki-tepki fonksiyonları Grafik 2'de sunulmuştur.

Grafik 2. Etki-Tepki Fonksiyonları

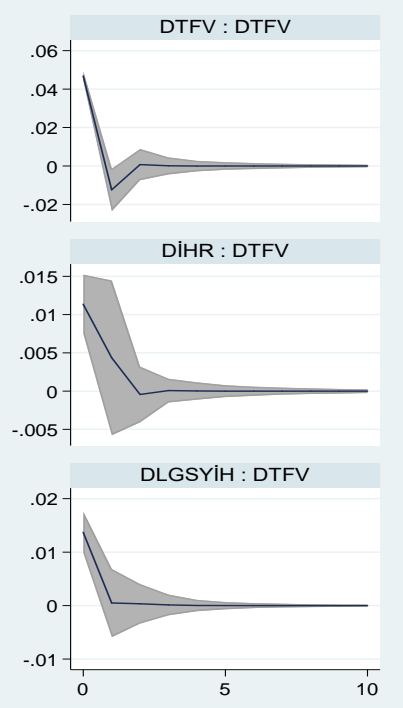

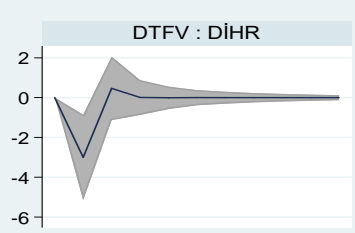

DIHR : DïHR

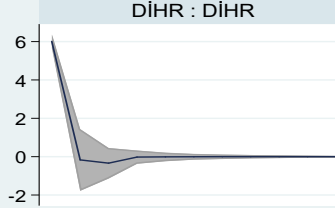

DLGSYIH : DïR

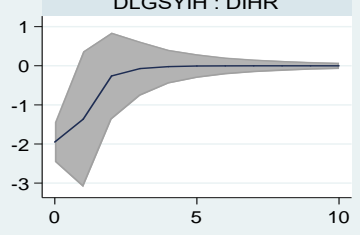

DTFV : DLGSYIH

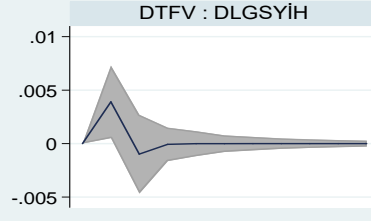

DIHR : DLGSYIH
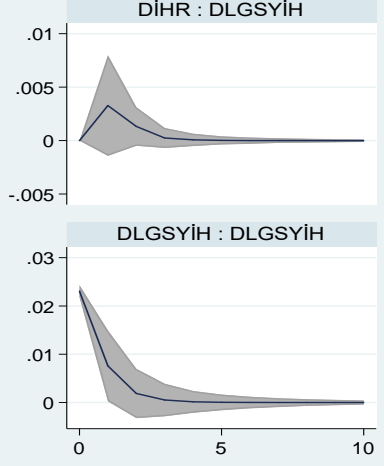
Etki-tepki grafikleri incelendiğinde, toplam faktör verimliliğinde meydana gelen bir birimlik pozitif bir şoka karşı ihracat ilk dönemlerde negatif bir tepki vermekte, 2. dönemden itibaren bu tepki ortadan kalkmakta, 3. dönemde pozitife dönmekte ve başlangıç değerinden yüksek bir değerde periyodu tamamlamaktadır. Toplam faktör verimliliğinde meydana gelen pozitif şoka GSYİH başlangıçta pozitif bir tepki vermekte, 2 . dönemden itibaren bu etki azalmakta ve 4 . dönemden itibaren ise ortadan kalkmaktadır.

İhracatta meydana gelen pozitif bir şoka GSYİH ilk dönemlerde pozitif tepki vermekte, 3 . dönemden itibaren bu etki ortadan kalkmaktadır. İhracatta meydana gelen pozitif bir şoka toplam faktör verimliliği ilk dönemlerde negatif bir tepki vermekte, 3 . dönemden itibaren bu tepki ortadan kalkmaktadır.

GSYİH'de meydana gelen pozitif bir şoka toplam faktör verimliliği ilk dönemlerde negatif bir tepki vermekte ve 3. dönemden itibaren bu negatif etki kalıcı olmaktadır. GSYİH'de meydana gelen bir birimlik pozitif bir şoka, ihracat ilk dönemlerde pozitif bir tepki vermekte ve 3. dönemden sonra bu tepki kalıcı olmaktadır.

\section{Granger Nedensellik Testi}

Etki-tepki analizlerinin ardından VAR modelinde son aşama Granger nedenselliğinin tespit edilmesi aşamasıdır. Granger nedensellik testi iki değişken arasındaki ilişkinin varlığını ve yönünü test etmek için kullanılır. Bu ilişki tek yönlü veya çift yönlü olabilir. Değişkenler arasında gecikmeli ilişkilerin varlığ durumunda bu ilişkinin yönünü açıklamak için Granger tarafından geliştirilmiş bir testtir. Granger'e göre Y'nin öngörüsü, X'in geçmiş değerlerinin kullanıldığ 1 durumda, $X$ 'in geçmiş değerlerinin kullanılmadığ 1 duruma göre daha başarılı ise $X$, Y'nin Granger nedenidir (Granger, 1988: 554). Granger nedensellik analizinde değişkenler arasındaki gecikmeli ilişkiler ele alındığından, öncelikli olarak gecikme uzunluğunun tespit edilmesi gerekmektedir. Granger tarafından geliştirilen testin genel gösterimi aşağıdaki gibidir.

$y_{i t}=\alpha_{i}+\sum_{k=1}^{k} \gamma(k) y_{i t-k}+\sum_{k=1}^{k} \beta^{(k)} x_{i t-k}+\varepsilon_{i t}$

Burada $\alpha_{i}$ birime özgü etkileri ifade etmektedir. $\gamma^{k}$ ve $\beta^{k}$ bütün birimler için aynı kabul edilmektedir. Buna göre, yapılan Granger nedensellik testi sonuçları Tablo 9'da sunulmaktadır.

Tablo 9. Granger Nedensellik Testi Sonuçları

\begin{tabular}{|l|l|c|c|c|}
\hline Eșitlik & Dişlanan & Ki-kare & Serbestlik Derecesi & Olasilık > Ki-kare \\
\hline \multirow{3}{*}{ DLGSYİH } & DIHR & 0.981 & 1 & 0.322 \\
\cline { 2 - 5 } & DTFV & 4.623 & 1 & 0.032 \\
\cline { 2 - 5 } & Tümü & 5.722 & 2 & 0.057 \\
\hline \multirow{3}{*}{ DiHR } & DLGSYİH & 0.112 & 1 & 0.738 \\
\cline { 2 - 5 } & DTFV & 7.450 & 1 & 0.006 \\
\cline { 2 - 5 } & Tümü & 13.642 & 2 & 0.001 \\
\hline \multirow{3}{*}{ DTFV } & DLGSYİH & 3.067 & 1 & 0.080 \\
\cline { 2 - 5 } & DIHR & 2.317 & 1 & 0.128 \\
\cline { 2 - 5 } & Tümü & 6.400 & 2 & 0.041 \\
\hline
\end{tabular}

Granger nedensellik analizinde Ho hipotezi değişkenler arasında Granger nedenselliği olmadiğl şeklindedir. Alternatif hipotez ise değişkenler arasında Granger nedenselliği vardır şeklinde kurulur. İlk satırda yer alan sonuçlara göre 
ihracattan GSYİH'ye doğru bir Granger nedenselliği bulunmamakta iken, toplam faktör verimliliğinden GSYİH'ye doğru bir Granger nedenselliği bulunmaktadır. İhracatın bağımlı değişken olduğu eşitlikte, toplam faktör verimliliğinin ihracatın Granger nedeni olduğu görülmektedir. Toplam faktör verimliliğinin bağıml değişken olduğu modelde ise, GSYİH'nin \%10 anlamlılık düzeyinde ihracatın Granger nedeni olduğu sonucuna varılmaktadır. Özet olarak, elde edilen sonuçlara göre toplam faktör verimliliğinden ihracata doğru tek yönlü, GSYİH ile toplam faktör verimliliği arasında ise çift yönlü Granger nedenselliği bulunmaktadır.

\section{SONUÇ}

Toplam faktör verimliliği, üretilen çıktının artmasına neden olan temel faktörlerden biridir. Bu kavram, günümüzde büyümenin başlıca belirleyicisi durumunda olan verimlilik kavramı için de kullanılabilecek başlıca açıklayıcı tanımlamadır ve bu bağlamda ülkelerin gelir düzeyindeki farklılıkları ortaya koyması açısından dikkat çekicidir. Literatürde toplam faktör verimliliği ile ekonomik büyüme arasındaki ilişkiyi inceleyen çok sayıda çalışma bulunmakla birlikte, yine büyümenin önemli belirleyicilerinden biri olan ihracatla ilişkisi bağlamında inceleyen çalışma sayısı azdır. Bu çalışmada, bu üç büyüklük arasındaki ilişki üst orta gelirli gelişmekte olan ülkeler için araştırılmıştır.

İhracat, toplam faktör verimliliği ve büyüme birbiriyle ilişkili büyüklüklerdir. Büyüme ya da gelir artışı verimlilik düzeylerinde artışlara neden olmakta, verimlilik arttıkça da ülkelerin ihracatında artışlar ortaya çıkmaktadır. Bu çalışmada da, benzer şekilde orta gelirli gelişmekte olan ülkelerde toplam faktör verimliliği ve ihracat arasında toplam faktör verimliliğinden ihracata doğru tek yönlü nedensellik ilişkisi bulunmuştur. Ayrıca, yine bu ülkelerde toplam faktör verimliliği ve büyüme arasında çift yönlü nedensellik tespit edilmiştir.

Gelişmekte olan ülkeler, adı üzerinde gelişmelerini ilerletmek, kalkınmış ülkeler düzeyine çıkmak isteyen ülkelerdir. Bunun da yolu, özellikle katma değeri yüksek sanayi ürünü üretip ihraç etmekten geçmektedir. Bu bağlamda, adı geçen ülkeler yeterli rekabet gücüne ulaşmak, ihracat ve gelir düzeylerini yükseltmek istiyorlarsa, faktör verimliliklerini arttırmak zorundadır. Bunun için de araştırma geliştirmeye daha fazla kaynak ayırmaları, bilim ve teknolojiye yatırım yapmaları ve özellikle işgücünün niteliğini artırmaya yönelik çalışmalara ağırlık vermeleri gerekmektedir.

\section{KAYNAKÇA}

Abrigo, M. R., \& Love, I. (2016). Estimation of Panel Vector Autoregression in Stata. The Stata Journal, Vol. 16, No. 3, 778-804

Ajmi, A. N., Aye, G. C., Balcilar, M., and Gupta, R. (2015). Causality Between Exports and Economic Growth in South Africa: Evidence From Linear and Nonlinear Tests. The Journal of Developing Areas, Vol. 49, No. 2, 163-181.

Akkoç, G. K., Akkoç, U. ve Yücel, Ö. F. (2018), BRICS-T Ülkelerinde Toplam Faktör Verimliliği ve Teknoloji Transferi. Uluslararası Íktisadi ve İdari Incelemeler Dergisi, Cilt 21, 101-118.

Aktaş, C. (2009), Türkiye'nin İhracat, İthalat ve Ekonomik Büyüme Arasındaki Nedensellik Analizi, Kocaeli Üniversitesi Sosyal Bilimler Enstitüsü Dergisi, Cilt 18, 2009/2, 35-47.

Alancıoğlu, E. ve Şit, M. (2019), BRICS Ekonomilerinde Toplam Faktör Verimliliği ile Ekonomik Büyüme İlişkisinin Panel Veri Analizi: 2000-2016 Dönemi. Akademik Araştırmalar ve Çalışmalar Dergisi, Cilt 11, Sayı 20, 29-40. 
Albiman, M. and Suleiman, N. N. (2016). The Relationship Among Export, Import, Capital Formation and Economic Growth in Malaysia. Journal of Global Economics, Vol. 4, No. 2, 23754389.

Aslan, A. ve Topcu, E. (2018). The Relationship Between Export and Growth: Panel Data Evidence From Turkish Sectors. Economies, Cilt 6, Say1. 2, 22.

Awokuse, T. O. (2008). Trade Openness and Economic Growth: Is Growth Export-led or Importled?. Applied Economics, Vol. 40, No. 2, 161-173.

Bahar, D. (2017). Productivity is Key to Economic Growth: Why is it Slowing Down in Advanced Economies? https://www.brookings.edu, Erişim Tarihi: 15.06.2020

Bai, J. and Ng, S. (2004). A Panic Attack on Unit Root s and Cointegration, Econometrica, Vol. 42, No. 4, 1127-1177.

Bakari, S. (2017). The Relationship Between Export, Import, Domestic Investment and Economic Growth in Egypt: Empirical Analysis. Euro Economica, Vol. 36, No. 2, 34-43.

Bal, H., Çiftçi, H., İşcan, E. ve Serin, D. (2016). İhracata Dayalı Büyüme: Teknolojik Bakış. The Export-Led Growth: A Technological View. International Conference on Eurasian Economies, Kaposvár-Hungary, 29-31 August 2016, Proceedings Book, Beykent University Publications, 311-316.

Bhattacharya, M. and Bhattacharya, S. N. (2016). International Trade and Economic Growth: Evidences From The BRICS. Journal of Applied Economics \& Business Research, Vol. 6, No. 2, 150-160.

Breuer, J. B., McNown, R. and Wallace, M. (2002). Series-specific Unit Root Tests with Panel Data. Oxford Bulletin of Economics and Statistics, Vol. 64, No. 5, 527-546.

Chang, T., Simo-Kengne, B. D. and Gupta, R. (2013). The Causal Relationship between Exports and Economic Growth in the Nine Provinces of South Africa: Evidence from Panel-Granger Causality Test. International Journal of Economic Policy in Emerging Economies, Vol. 6, No. 3, 2013, 296-310

Chow, P. C. (1987). Causality Between Export Growth and Industrial Development: Empirial Evidence from the NICs. Journal of Development Economics, Vol. 26, No. 1, 55-63.

Ekanayake, E. M. (1999). Exports and Economic Growth in Asian Developing Countries: Cointegration and Error-correction Models. Journal of Economic Development, Vol. 24 No. 2, 43-56.

Giles, J.A. and Willams, C.L., (1999), "Export-led Growth: A Survey of the Empirical Literature and some Non-causality Results, The Journal of International Trade \& Economic Development, Vol. 9, No. 3, 261-337.

Gömleksiz, M., Şahbaz, A. ve Mercan, B. (2017). Toplam Faktör Verimliliğinin Belirleyicileri Üzerine Ampirik Bir İnceleme: Seçilmiş OECD Ülkeleri Örneği. Eskişehir Osmangazi Üniversitesi İktisadi ve İdari Bilimler Dergisi, Cilt 12, Say1 2, 65-82.

Granger, C. (1988). Causality, Cointegration and Control. Journal of Economic Dynamics and Control, Vol. 12, (2-3), 551-559.

Güriş, B. (2018). Panel Vektör Otoregresif Modeller ve Panel Nedensellik. (Ed. Selahattin Güriş), Uygulamalı Panel Veri Ekonometrisi, İstanbul: DER Yayınları, 279-292.

Hacker, R. S. and Hatemi-J, A. (2003), How Productivity and Domestic Output are Related to Exports and Foreign Output in the Case of Sweden. Empirical Economics 28, 767-782.

Hatemi-J, A. (2002). Export Performance and Economic Growth Nexus in Japan: A Bootstrap Approach. Japan and the World Economy, Vol. 14, No. 1, 25-33.

İnal, A. (2009). Durağan Olmayan Paneller ve Bir Uygulama. Yayımlanmamış Yüksek Lisans Tezi. Adana: Çukurova Üniversitesi Sosyal Bilimler Enstitüsü, Adana.

Jordaan, A. C. and Eita, J. H. (2007). Export and Economic Growth in Namibia: A Granger Causality Analysis. South African Journal of Economics, 75(3), 540-547.

Kim, S. and Lim, H. (2005). Dynamic Determinants of Korean Productivity Changes: With Emphasis on Trade. East Asian Economic Review, 9(2), 3-45.

Kim, S., Lim, H. and Park, D. (2009). Imports, Exports and Total Factor Productivity in Korea, Applied Economics, Vol. 41, No. 14, 1819-1834. 
Konya, L. (2004). Export-led Growth, Growth-driven Export, Both or None? Granger Causality Analysis on OECD Countries. Applied Econometrics and International Development, Vol. 4, No. 1, 73-94

Maddala G.S. and Wu, S. (1999). A Comparative Study of Unit Root Tests with Panel Data and a New Simple Test, Oxford Bulletin of Economics and Statistic, Vol. 61, No. 1, 631-652.

Nordhaus, W. (2005). The Sources of The Productivity Rebound and The Manufacturing Employment Puzzle. NBER Working Paper, No. 11354, https://www.nber.org/papers, Erişim Tarihi: 20.06.2020

Pesaran, H. M. (2003). A Simple Panel Unit Root Test in the Presence of Cross Section Dependence, Cambridge Working Papers in Economics 0346.

Pesaran, H. M. (2004). General Diagnostic Tests for Cross Section Dependence in Panels. IZA Discussion Paper, No. 1240.

Pesaran, H. M. (2007). A Simple Panel Unit Root Test in the Presence of Cross Section Dependence, Journal of Applied Econometrics Vol. 22, No. 2, 265-312.

Paul, S. and Chowdhury, K. (1995). Export-led Growth Hypothesis: Some Empirical Testing. Applied Economics Letters, Vol. 2, No. 6, 177-179.

Ramos, F. F. R. (2001). Exports, Imports, and Economic Growth in Portugal: Evidence From Causality and Cointegration Analysis. Economic Modelling, Vol. 18, No. 4, 613-623.

Rath, B. N. and Akram, V. (2017). Export Diversification and Total Factor Productivity Growth in Case of South Asian Region. Journal of Social and Economic Development, Vol. 19, No. 1, 196-210.

Santos, P. G., Ribeiro, A. P. and Carvalho, V. M. (2013). Export-led growth in Europe: Where and What to Export?. FEP Working Papers, No. 479.

Solow, R. M. (1956). A Contribution to The Theory of Economic Growth. The Quarterly Journal of Economics, Vol. 70, No. 1, 65-94.

Şak, N. (2018). Panel Birim Kök Testleri. (Ed. Selahattin Güriş), Uygulamalı Panel Veri Ekonometrisi İstanbul: DER Yayınları, 259-314.

Thangavelu, S. M. and Rajaguru, G. (2004). Is There an Export or Import-led Productivity Growth in Rapidly Developing Asian Countries? A Multivariate VAR Analysis. Applied Economics, Vol. 36, No. 10, 1083-1093.

Trošt, M. and Bojnec, Š. (2016). Export-led Growth: The Case of The Slovenian and Estonian Economies. Post-Communist Economies, Vol. 28, No. 3, 373-383.

Uçak, H. ve Arısoy, İ. (2011). Türkiye Ekonomisinde Verimlilik, İhracat ve İthalat Arasındaki Nedensellik İlişsisinin Analizi. Ege Akademik Bakış, Cilt 11, Sayı 4, 639-651.

Vergil, H. ve Abasız, T. (2008). Toplam Faktör Verimliliği, Hesaplanması ve Büyüme İlişkisi: Collins Bosworth Varyans Ayrıştırması. Kocaeli Üniversitesi Sosyal Bilimler Dergisi, Sayı 16, 160188.

World Bank (2020). https://datahelpdesk.worldbank.org/knowledgebase/articles/906519-worldbank-country-and-lending-groups, Erişim Tarihi: 21.06.2020

Xu, Z. (1996). On the Causality Between Export Growth and GDP Growth: An Empirical Reinvestigation. Review of International Economics, 4(2), 172-184.

Yalçınkaya, Ö. (2018). Toplam Faktör Verimliliğinin Belirleyicileri: G-7 ve Seçilmiş Yükselen Piyasa Ekonomileri Üzerine Bir Uygulama (1992-2013). Anadolu Üniversitesi Sosyal Bilimler Dergisi, Cilt 18, Sayı 3, 41-60.

Yaprakl1, S. (2007). Causality Between Exports and Economic Growth: An Econometric Analysis on Turkey. METU Studies in Development, Cilt 34, Sayı 1, 97- 112.

\section{SUMMARY}

Total factor productivity expressed as a combined effect of causes except for labor and capital increases in production is one of the important concepts that explain the reasons for the growth differences between countries. The increase in total factor productivity, that is, obtaining the same level of output with fewer 
resources, allows the existing resources to be evaluated in other productive areas. In this way, economic activities increase and develop. On the other hand, exports which is an activity bringing foreign exchange is considered as the engine of economic growth in this aspect and contributes to the acceleration of the development of the countries in the long-term. At the same time, it is stated that economic growth also facilitates the export of countries by creating a comparative superiority through productivity and efficiency increase. Therefore, total factor productivity, growth and export are interrelated concepts.

Although there are many studies in the domestic and foreign literature on the relationship between total factor productivity-growth and especially exportgrowth, there are not many studies examining the relationship between the three sizes. In this study, the relationship between the three mentioned sizes is examined empirically in the case of developing countries. It is considered that the study will contribute to the literature in this sense. In addition, the fact that econometric analysis is conducted in the case of upper-middle-income developing countries reveals the difference of the study from other studies in this field.

In the study in which is used the data of 1991-2017 of 26 countries in the upper-middle-income group according to the classification of the World Bank, firstly, horizontal cross-section dependence in panel dataset is checked with Pesaran's CD-test. Then, in order to test the stationarity of the series according to the results, test results of the MW test and Pesaran's CIPS are obtained from the first- and second-generation unit root tests at the same time and the stationarity control of the series is performed. After determining the stationarity of the series, the appropriate lag length is determined in order to establish the VAR model; with this lag length, parameter estimation is made by using the GMM method. After the parameter estimation, it is checked whether the model meets the dynamic stability condition. After providing the dynamic stability condition, effect-response graphics are obtained and variance decomposition is made. In the last stage of the empirical analysis, the existence and direction of the relationship between the specified variables are determined by the Granger causality test.

As a result of the analysis, a one-way causality relationship from total factor productivity to export is found between total factor productivity and exports in upper-middle-income developing countries. Also, in these countries, bidirectional causality is found between total factor productivity and growth. According to these results, it is seen that total factor productivity in developing countries is one of the main causes of growth and exports. Therefore, the mentioned countries have to increase their factor productivity if they want to reach sufficient competitiveness and increase their export and income levels. For this, they need to allocate more resources for research and development, invest in science and technology, and especially focus on studies to improve the quality of the labor force. 